\title{
Molten Salt Synthesis of Conducting and Superconducting Ceramics
}

\author{
K. Kolincio, K. Gdula, A. Mielewczyk, T. Izdebski and M. Gazda \\ Faculty of Applied Physics and Mathematics, Gdańsk University of Technology \\ G. Narutowicza 11/12, 80-233 Gdańsk, Poland
}

\begin{abstract}
The functional properties of many interesting materials are the best if the materials are dense and have ordered or partially ordered microstructure. Obtaining such materials most often requires very time and energy consuming technologies, like high temperature and high pressure synthesis. In this work the applicability of the molten salt synthesis method, which is a simple and cheap technology, to the synthesis of the selected high temperature superconductors, ionic conductors and dielectric materials have been discussed.
\end{abstract}

PACS numbers: 74.72.Gh, 81.05.Je

\section{Introduction}

Manufacturing of such materials like high temperature superconductors, ionic conductors and ceramics of dielectric, piezoelectric or other properties requires controlling the microstructure. Their functional properties are the best if the materials are dense and have ordered or at least partially ordered microstructure. It may be achieved by using the so-called template grain growth (TGG) technology [1]. In this method, a type of a composite sample is prepared. A composite consists of a small amount of single crystals (templates) dispersed and aligned in a matrix of very fine grains. Sintering of the composite results in the material densification and growth of the templates. In order to obtain the ceramics with ordered grains, the crystals which serve as templates should be easily aligned. Therefore, they should have a plate-like or rod-like shape. One of the methods of producing such crystals is a molten-salt synthesis (MSS).

In this work we present preliminary results of the application of the molten salt synthesis to the (Bi,Pb)$\mathrm{Ca}-\mathrm{Sr}-\mathrm{Cu}-\mathrm{O}$ high temperature superconductors, $\mathrm{Bi}-\mathrm{Ca}-$ $\mathrm{Co}-\mathrm{O}$ thermoelectric dielectrics and $\mathrm{Ba}-(\mathrm{Ce}, \mathrm{Zr})-\mathrm{O}$ and (Ca,La)-Nb-O proton conducting materials. The applicability of the MSS method to the studied materials has been discussed.

\section{Experimental}

The details of the molten salt synthesis of the particular samples depended on their composition, however the general sequence of steps was similar in all cases. The following samples were prepared: $\mathrm{Bi}-\mathrm{Ca}-\mathrm{Co}-\mathrm{O}$ single crystals, 2223 powder superconductors and $\mathrm{Ba}-(\mathrm{Ce}, \mathrm{Zr})-\mathrm{O}$ and $(\mathrm{Ca}, \mathrm{La})-\mathrm{Nb}-\mathrm{O}$ powder proton conducting materials. For all samples, the phase composition, crystallite anisotropy and size were studied by X-ray diffraction (XRD) and scanning electron microscopy (SEM).
$\mathrm{Bi}-\mathrm{Ca}-\mathrm{Co}-\mathrm{O}$ single crystals were prepared on the basis of the work of Luo et al. [2]. First, polycrystalline $\mathrm{Bi}_{2} \mathrm{Ca}_{2} \mathrm{Co}_{2} \mathrm{O}_{y}$ was prepared from $\mathrm{Bi}_{2} \mathrm{O}_{3}, \mathrm{CaCO}_{3}$ and $\mathrm{Co}_{3} \mathrm{O}_{4}\left(800^{\circ} \mathrm{C}\right.$ for $\left.12 \mathrm{~h}\right)$. The pellets were ground and mixed with $\mathrm{KCl}$ in approximately 1:6 ratios. The mixture was heated at $900{ }^{\circ} \mathrm{C}$ for $20 \mathrm{~h}$ and slowly cooled down to $600{ }^{\circ} \mathrm{C}$. The single crystals were removed from molten salt bath by washing in distilled water.

The ceramic powder of $\mathrm{Bi}_{1.6} \mathrm{~Pb}_{0.4} \mathrm{Sr}_{2} \mathrm{Ca}_{2} \mathrm{Cu}_{3} \mathrm{O}_{x}$ and $\mathrm{Bi}_{1.6} \mathrm{~Pb}_{0.4} \mathrm{Sr}_{1.8} \mathrm{Zr}_{0.2} \mathrm{Ca}_{2} \mathrm{Cu}_{3} \mathrm{O}_{x}$ was prepared in a conventional solid-state reaction $\left(640^{\circ} \mathrm{C}\right.$ for $4 \mathrm{~h} \rightarrow 720^{\circ} \mathrm{C}$ for $6 \mathrm{~h}$ $\rightarrow 780^{\circ} \mathrm{C}$ for $20 \mathrm{~h} \rightarrow 820^{\circ} \mathrm{C}$ for $45 \mathrm{~h}$ ). After that the powder was ground, mixed with $\mathrm{KCl}$ in 1:2 ratio and heated at $830^{\circ} \mathrm{C}$ for $2 \mathrm{~h}$. Then, the $\mathrm{KCl}$ was removed and the powder was pressed and sintered at $830^{\circ} \mathrm{C}$ for various periods of time.

Two proton conductors, $\mathrm{La}_{0.8} \mathrm{Mg}_{0.2} \mathrm{NbO}_{4}$ and $\mathrm{BaCe}_{0.8} \mathrm{Y}_{0.1} \mathrm{Zr}_{0.1} \mathrm{O}_{3}$, were prepared in the following way: the substrates were ball milled with $\mathrm{KCl}$ or a mixture of $\mathrm{KCl}$ and $\mathrm{NaCl}$ and then heat treated at $1100^{\circ} \mathrm{C}$ for $3 \mathrm{~h}$. Then, the salt was removed from the products, the powder was pressed into pellets and calcinated in various temperatures from $900^{\circ} \mathrm{C}$ to $1200^{\circ} \mathrm{C}$.

\section{Results and discussion}

The molten salt synthesis is an attractive technology because of its simplicity, low price and short reaction times. However, its applicability is limited to the materials which do not react with the salt. Another factor limiting its application is the melting temperature of the synthesized materials and their stability. In this work several materials were synthesized by the MSS methods. Due to that, the presented results are inevitably very brief and will not cover all the relevant properties of the studied materials.

Figures 1-3 show the XRD results obtained for the studied samples. Figure 4 presents examples of optical and SEM images. It can be seen that $\mathrm{La}_{0.8} \mathrm{Mg}_{0.2} \mathrm{NbO}_{4}$ 


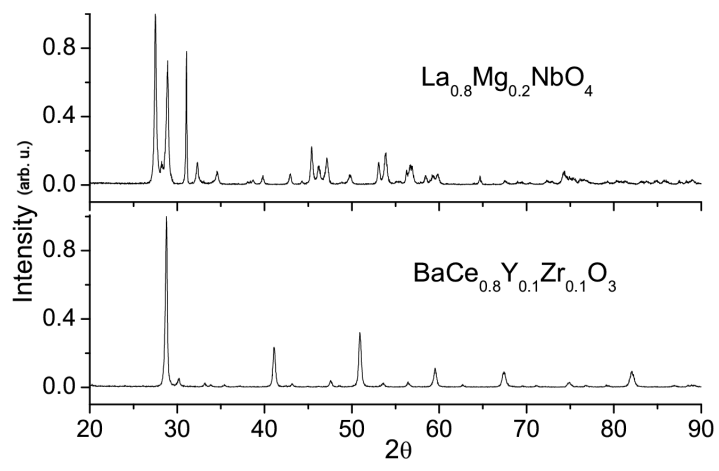

Fig. 1. X-ray diffraction pattern of the $\mathrm{La}_{0.8} \mathrm{Mg}_{0.2} \mathrm{NbO}_{4}$ and $\mathrm{BaCe}_{0.8} \mathrm{Y}_{0.1} \mathrm{Zr}_{0.1} \mathrm{O}_{3}$ samples obtained with the MSS method.

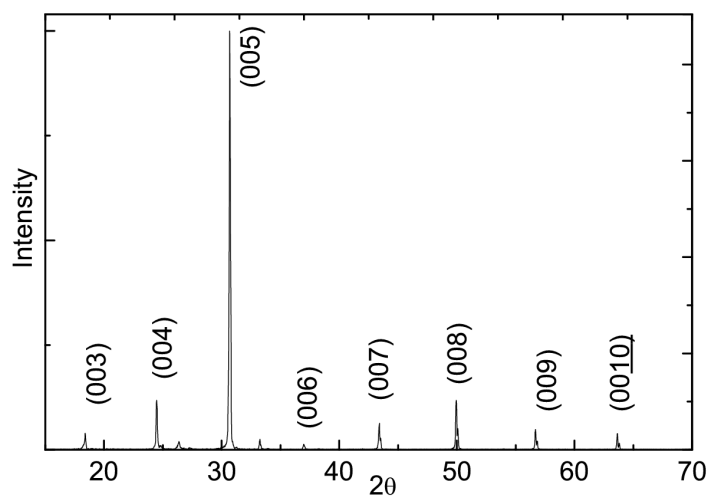

Fig. 2. X-ray diffraction pattern of the $\mathrm{Ca}_{2} \mathrm{Bi}_{1.4} \mathrm{Co}_{0.6} \mathrm{O}_{4}\left(\mathrm{CoO}_{2}\right)_{1.69}$ single crystal obtained with the MSS method.

and $\mathrm{Bi}-\mathrm{Ca}-\mathrm{Co}-\mathrm{O}$ samples are single-phase. Both XRD and SEM results indicate that the crystallites of the LNO ceramics obtained by MSS are larger and less isotropic than these obtained by the conventional solid-state (SS) synthesis (MSS: $2-3 \mu \mathrm{m}$, SS: $1-2 \mu \mathrm{m}$ ). The difference between the shapes of the MSS and SS crystallites can

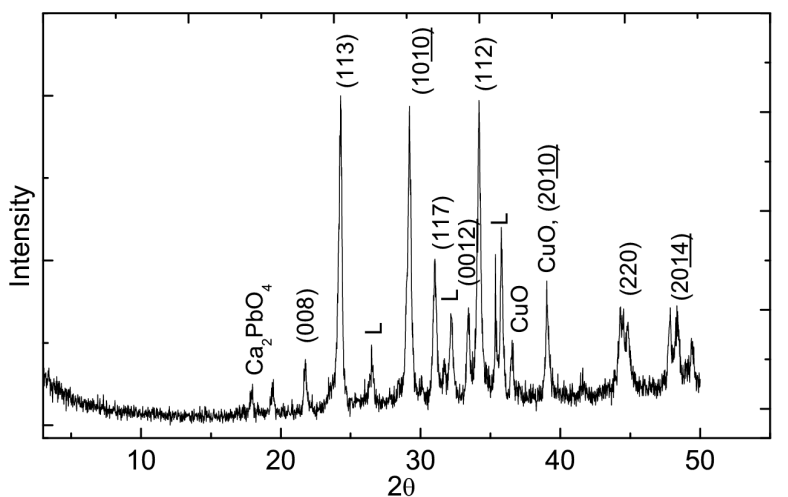

Fig. 3. X-ray diffraction pattern of the 2223 ceramics obtained with the MSS method. be seen directly in Fig. 4. Another advantage of the MSS method in comparison with the conventional one is that it requires approximately twice less time of high temperature annealing. Synthesis of another proton conducting perovskite $\mathrm{BaCe}_{0.8} \mathrm{Y}_{0.1} \mathrm{Zr}_{0.1} \mathrm{O}_{3}$ with the MSS required a nonstoichiometric amount of barium in order to obtain a single-phase ceramics. Also in this case the MSS crystallites were larger (MSS: $1-2 \mu \mathrm{m}, \mathrm{SS}: 0.1-0.5 \mu \mathrm{m}$ ) and their shape was elongated with the axis approximately parallel to (100) and (001). Next, MSS synthesis of the 2223 was partially successful. Crystallites of the obtained ceramics were large and the samples showed the texture, but they were not single-phase. Despite that, their superconducting properties were quite promising. Finally, the example of an entirely successful MSS was synthesis of large (about $4 \times 4 \times 0.1 \mathrm{~mm}^{3}$ ) single crystals of $\mathrm{Ca}_{2} \mathrm{Bi}_{1.4} \mathrm{Co}_{0.6} \mathrm{O}_{4}\left(\mathrm{CoO}_{2}\right)_{1.69}$ composition [2].

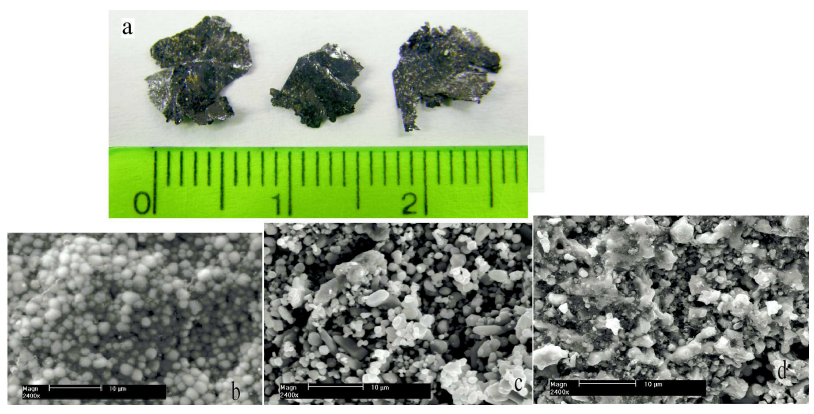

Fig. 4. Optical image of $\mathrm{Ca}_{2} \mathrm{Bi}_{1.4} \mathrm{Co}_{0.6} \mathrm{O}_{4}\left(\mathrm{CoO}_{2}\right)_{1.69}$ single crystals (a); SEM micrographs of the proton conductors $\mathrm{La}-\mathrm{Nb}-\mathrm{O}$ samples prepared by a solid state synthesis (b), and the MSS method (c), and the $\mathrm{Ba}-\mathrm{Ce}-$ $\mathrm{Zr}-\mathrm{O}$ sample obtained by the MSS method (d).

The molten salt synthesis itself is an effective method of obtaining either single crystals or a ceramic powder composed of crystallites or clusters of crystallites. As can be seen in Fig. 4 the ceramics obtained by pressing and sintering of the MSS powder are porous.

\section{Conclusions}

Application of the MSS to obtain the materials we have studied is promising. In all cases crystallites of the ceramic samples obtained with the MSS method were larger and of different shape than those obtained with the solid-state synthesis. Further studies, especially aimed at diminishing the sample porosity, are necessary.

\section{References}

[1] H. Amorín, J. Ricote, J. Holc, M. Kosec, M. Alguer, J. Eur. Ceram. Soc. 28, 2755 (2008).

[2] X.G. Luo, Y.C. Jing, H. Chen, X.H. Chen, J. Cryst. Growth 308, 309 (2007). 